\title{
Out-of-Hospital Cardiac Arrest: Better Prognosis When You Know the Cardiac Rhythm and You Can Shock it
}

\section{Editorial}

Out-of-hospital cardiac arrest (OHCA) is a major event and lethal entity as an outcome of ischemic heart disease, and remains a major public health issue worldwide [1]. The annual incidence rate and clinical outcomes are being studied globally as significant indicators of national health. As expected, reports on the incidence of OHCA around the world vary widely. According to a review and a worldwide meta-analysis, there is an incidence of cardiac arrest that varies from 45 to 84 per population of 100,000 people [2,3]. In addition, large cumulative meta-analysis conducted to date documented a mean survival to hospital admission rate of $24 \%$ and a low hospital discharge rate of only $8 \%$ [2-5]. This low rate of survival to hospital discharge ranges from $4.5 \%$ to $10.7 \%$ [613]. The variation may be due to different definitions, outcome measures, study sites, and populations.

Acute myocardial infarction (AMI) is known to be the most common cause of sudden cardiac arrest, and successful primary percutaneous coronary intervention (PCI) may improve survival in these patients [14-20]. Even if the role of PCI in OHCA might be controversial, diagnosing and treating an ongoing $\mathrm{AMI}$ as early as possible after OHCA is crucial to lowering mortality [21-24]. Accuracy in deciding whether to perform primary PCI is classically based on electrocardiographic (ECG) findings after recovery of spontaneous circulation. However, ECG changes may be difficult to interpret in patients resuscitated from OHCA, and the predictive value of ECG for acute coronary artery occlusion in this setting is poor [25]. Hence, it is not easy to properly select candidates for primary PCI especially in patients without STsegment elevation. Although echocardiography and biomarkers are commonly used in OHCA patients, their role in predicting the etiology of cardiac arrest has not been adequately evaluated. The OHCA etiology is not always found, since there is great number of patients who has the first contact with health professionals at the event of the cardiac arrest itself. In addition, the predictive value of diagnostic tools for acute coronary artery occlusion after the recovery of spontaneous circulation may differ in different ethnics making a global comparison difficult [26,27].

In this issue of the Journal of Cardiology and Current Research, Comisario RM [28] studied 88 cardiac arrest patients admitted to the emergency room of the Corrientes Cardiology Institute. Demographic information was collected, as well as, suspected cardiac arrest etiology, heart rhythm on admission, hospital survival, and 6 months survival. The findings are interesting and well compared to those of the literature. Cardiovascular causes of cardiac arrest corresponded to 39.8\%. In-hospital survival was $25 \%$, and 6 months survival was $12,5 \%$. Variables associated to worse prognosis in the univariateanalysis were non-cardiovascular cardiac arrest (OR 8.8; CI 1.7 - 43; p=0.003), unknown cause of cardiac arrest (OR 1.79; CI $1.46-2.18$; $\mathrm{p}=0.003$ ), but no variable was an independent predictor in multivariate analysis. In his

Volume 6 Issue 3 - 2016
Osmar Antonio Centurión 1,2*
${ }^{1}$ Department of Health Sciences' Investigation, Sanatorio
Metropolitano, Fernando de la Mora, Paraguay
${ }^{2}$ Cardiology Division, First Department of Internal Medicine,
Clinic Hospital, Asunción National University, San Lorenzo,
Paraguay
*Corresponding author: Osmar Antonio Centurión,
Professor of Medicine, Asuncion National University,
Department of Health Sciences' Investigation, Sanatorio
Metropolitano, Teniente Ettiene 215 c/ Ruta Mariscal
Estigarribia, Fernando de la Mora, Paraguay, Tel: 595-21-
498200; Fax: 595-21-205630;
Email: osmarcenturion@hotmail.com
Received: July 21, 2016 | Published: August 02, 2016

report [28], the mean survival was 76 days, and survival in patients discharged alive was 297 days (median 161 days). At follow-up patients had worse prognosis if admitted for non-cardiovascular origin of cardiac arrest $(p=0.003)$, patients without clear origin of cardiac arrest $(\mathrm{p}=0.0001)$; and patients with non-shockable rhythms on admission $(\mathrm{p}=0.009)$. Therefore, Comisario RM concluded that there is a worse prognosis in patients admitted for cardiac arrest secondary to non-cardiovascular causes, as well as, in patients without a clear origin of the cardiac arrest, and in those with non-shockable rhythms [28]. Hence, there is a better prognosis when you know the cardiac rhythm and you can shock it in OHCA patients. Indeed, it is much better to know what to treat than not knowing what made you died suddenly.

These findings are quite similar to those reported worldwide. In general, western countries have more studies on this topic [613]. Nevertheless, some Asian countries like Japan, South Korea and Taiwan have also paid much attention to this problem in recent years [29-32]. A recent article on OHCA reported results from an investigation done in Taiwan in patients who were 15 years of age or older [31]. They found a 13\% probability of survival to hospital admission, and a 1-month survival rate of $17.3 \%$ among admitted OHCA patients [31]. A newer Taiwanese study investigated OHCA survival rates in a non-metropolitan area [32]. They demonstrated that the probability of survival on admission was $16.3 \%$, and the chance of surviving to discharge was only 1.4\% [32]. The CARES registry showed that the OHCA survival rate to hospital admission in patients with cardiac causes and pre-hospital CPR was 26\%, and the overall survival rate to hospital discharge was 10\% [33]. A ten year study in the 90s reviewing global OHCA survival rates reported that the survival rates to discharge in emergency care 
facilities were 6\% in North America, $9 \%$ in Europe, and $11 \%$ in Australia [2].

There is a clear decreasing trend in the incidence rate of OHCA worldwide. A recent study in Australia reported an OHCA incidence rate of 53 events per 100,000 person-years between the years 2004-2005, and a decreasing trend leading to a rate of 48 events per 100,000 person-years between the years 2009 2010 [34]. In contrast, a recent study in South Korea showed that the OHCA incidence rate increased from 38 events per 100,000 person-years in 2006 to 47 in 2010 [35]. While the incidence rates of OHCA in these countries had substantial differences ten years ago, they seemed to be reasonably comparable in recent years, suggesting a trend toward more similar patterns of prevention and hospital care delivery across countries. These findings in the literature suggest that the chance of survival to hospital discharge or among OHCA patients has improved over time globally. This might reflect improvement in skills, resources, training, and postresuscitation care in recent years.

It was observed that OHCA patients treated in advanced medical centers and those residing in metropolitan areas tended to have better survival chance. These findings are reasonable since metropolitan areas have more affluent healthcare resources for both pre-hospital services and post-resuscitation care. In addition, the medical centers may have more advanced technical support and training skills that are more effective in improving post-resuscitation care. Moreover, further advances in pathophysiologic knowledge and medical therapeutic maneuvers can help develop cardiovascular disease preventive strategies. Further information on factors associated with postOHCA prognosis can facilitate improvement in pre-hospital and in-hospital care to reduce morbidity and mortality in patients suffering OHCA.

\section{References}

1. Boyd TS, Perina DG (2012) Out-of-hospital cardiac arrest. Emerg Med Clin North Am 30(1): 13-23.

2. Berdowski J, Berg RA, Tijssen JG, Koster RW (2010) Global incidences of out-of-hospital cardiac arrest and survival rates: Systematic review of 67 prospective studies. Resuscitation 81(11): 1479-1487.

3. Sasson C, Rogers MA, Dahl J, Kellermann AL (2010) Predictors of survival from out-of-hospital cardiac arrest: a systematic review and meta-analysis. Circ Cardiovasc Qual Outcomes 3(1): 63-81.

4. Jones DL, Adams RJ, Brown TM, Carnethon M, Dai S, et al. (2010) Heart disease and stroke statistics-2010 update: a report from the American Heart Association. Circulation 121(7): e46-e215.

5. Go AS, Mozaffarian D, Roger VL, Benjamin EJ, Berry JD, et al. (2013) Heart disease and stroke statistics-2013 update: a report from the American Heart Association. Circulation 127(1): e6-e245.

6. Atwood C, Eisenberg MS, Herlitz J, Rea TD (2005) Incidence of EMStreated out-of-hospital cardiac arrest in Europe. Resuscitation 67(1): 75-80.

7. Roger VL, Go AS, Jones DML, Benjamin EJ, Berry JD, et al. (2012) Heart disease and stroke statistics-2012 update: a report from the American Heart Association. Circulation 125(1): e2-e220.
8. Rea TD, Eisenberg MS, Sinibaldi G, White RD (2004) Incidence of EMS-treated out-of-hospital cardiac arrest in the United States. Resuscitation 63(1): 17-24

9. Swagemakers JJDV, Gorgels AP, Arbouw WID, van Ree JW, Daemen MJ, et al. (1997) Out-of-hospital cardiac arrest in the 1990's: a populationbased study in Maastricht area on incidence, characteristics and survival. J Am Coll Cardiol 30(6): 1500-1505.

10. Cobb LA, Fahrenbruch CE, Olsufka M, Copass MK (2002) Changing incidence of out-of-hospital ventricular fibrillation, 1980-2000. JAMA 288(23): 3008-3013.

11. Nichol G, Thomas E, Callaway CW, Hedges J, Powell JL, et al. (2008) Regional variation in out-of-hospital cardiac arrest incidence and outcome. JAMA 300(12): 1423-1431.

12. Olasveengen TM, Sunde K, Brunborg C, Thowsen J, Steen PA, et al (2009) Intravenous drug administration during out-of-hospital cardiac arrest: a randomized trial. JAMA 302(20): 2222-2229.

13. Lindner TW, Søreide E, Nilsen OB, Torunn MW, Lossius HM (2011) Good outcome in every fourth resuscitation attempt is achievablean Ustein template report from the Stavanger region. Resuscitation 82(12): 1508-1513.

14. Spaulding CM, Joly LM, Rosenberg A, Monchi M, Weber SN, et al. (1997) Immediate coronary angiography in survivors of out-of-hospital cardiac arrest. N Engl J Med 336(23): 1629-1633.

15. Herlitz J, Engdahl J, Svensson L, Angquist KA, Silfverstolpe J, et al. (2006) Major differences in 1-month survival between hospitals in Sweden among initial survivors of out-of-hospital cardiac arrest. Resuscitation 70(3): 404-409.

16. Nolan JP, Laver SR, Welch CA, Harrison DA, Gupta V, et al. (2007) Outcome following admission to UK intensive care units after cardiac arrest: a secondary analysis of the ICNARC Case Mix Programme Database. Anaesthesia 62(12): 1207-1216.

17. Davies MJ, Thomas A (1984) Thrombosis and acute coronary-artery lesions in sudden cardiac ischemic death. N Engl J Med 310(18): 11371140 .

18. Davies MJ (1992) Anatomic features in victims of sudden coronary death. Coronary artery pathology. Circulation 85(1 Suppl): I19-I24.

19. Dumas F, Cariou A, Silberman SM, Grimaldi D, Vivien B, et al. (2010) Immediate percutaneous coronary intervention is associated with better survival after out-of-hospital cardiac arrest: insights from the PROCAT (Parisian Region Out of hospital Cardiac ArresT) registry. Circ Cardiovasc Interv 3(3): 200-207.

20. Park TK, Yang JH, Choi SH, Song YB, Hahn JY, et al. (2014) Clinical outcomes of patients with acute myocardial infarction complicated by severe refractory cardiogenic shock assisted with percutaneous cardiopulmonary support. Yonsei 2Med J 55(4): 9300-9307.

21. Anyfantakis ZA, Baron G, Aubry P, Himbert D, Feldman LJ, et al. (2009) Acute coronary angiographic findings in survivors of out-of-hospital cardiac arrest. Am Heart J 157(2): 312-318.

22. Garot P, Lefevre T, Eltchaninoff H, Morice MC, Tamion F, et al. (2007) Six-month outcome of emergency percutaneous coronary intervention in resuscitated patients after cardiac arrest complicating ST-elevation myocardial infarction. Circulation 115(11): 1354-1362.

23. Gorjup V, Radsel P, Kocjancic ST, Erzen D, Noc M (2007) Acute STelevation myocardial infarction after successful cardiopulmonary resuscitation. Resuscitation 72(3): 379-385. 
24. Neumar RW, Nolan JP, Adrie C, Aibiki M, Berg RA, et al. (2008) Postcardiac arrest syndrome: epidemiology, pathophysiology, treatment and prognostication. A consensus statement from the International Liaison Committee on Resuscitation (American Heart Association, Australian and New Zealand Council on Resuscitation, European Resuscitation Council, Heart and Stroke Foundation of Canada, InterAmerican Heart Foundation, Resuscitation Council of Asia, and the Resuscitation Council of Southern Africa); the American Heart Association Emergency Cardiovascular Care Committee; the Council on Cardiovascular Surgery and Anesthesia; the Council on Cardiopulmonary, Perioperative, and Critical Care; the Council on Clinical Cardiology; and the Stroke Council. Circulation 118(23): 2452-2483.

25. Zanuttini D, Armellini I, Nucifora G, Grillo MT, Morocutti G, et al. (2013) Predictive value of electrocardiogram in diagnosing acute coronary artery lesions among patients with out-of-hospital-cardiac-arrest Resuscitation 84(9): 1250-1254.

26. Khoo KL Tan H, Liew YM, Deslypere JP, Janus E (2003) Lipids and coronary heart disease in Asia. Atherosclerosis 169(1): 1-10.

27. Kim AS, Johnston SC (2011) Global variation in the relative burden of stroke and ischemic heart disease. Circulation 124(3): 314-323.

28. Comisario RM (2016) Out-of-hospital cardiac arrests in Corrientes Cardiology Institute. Prognostic factors and 6 months survival. J Cardiol Curr Res 6(3): 00203.

29. Hasegawa K, Tsugawa Y, Camargo CA, Hiraide A, Brown DF (2013) Regional variability in survival outcomes of out-of-hospital cardiac arrest: the All-Japan Ustein Registry. Resuscitation 84(8): 1099-1107.
30. Kim JY, Shin SD, Ro YS, Song KJ, Lee EJ, et al. (2013) Post-resuscitation care and outcomes of out-of-hospital cardiac arrest: a nationwide propensity score-matching analysis. Resuscitation 84(8): 1068-1077.

31. Dorji Harnod, Ming Ma MH, Chang WH, Chang RE, Chang CH (2013) Mortality Factors in Out-of-Hospital Cardiac Arrest Patients: A Nationwide Population-based Study in Taiwan. International Journal of Gerontology 7(4): 216-220.

32. Kuo CW, See LC, Tu HT, Chen JC (2014) Adult out-of-hospital cardiac arrest based on chain of survival in Taoyuan County, northern Taiwan. J Emerg Med 46(6): 82-90.

33. McNally B, Robb R, Mehta M, Vellano K, Valderrama AL, et al. (2011) Out-of-hospital cardiac arrest surveillance-Cardiac Arrest Registry to Enhance Survival (CARES), United States, October 1, 2005-December 31, 2010. MMWR Surveill Summ 60(8): 1-19.

34. Cheung W, Middleton P, Davies S, Tummala S, Thanakrishnan G, et al (2013) A comparison of survival following out-of-hospital cardiac arrest in Syndney, Australia, between 2004-2005 and 2009-2010. Crit Care Resusc 15(3): 241-246.

35. Ro YS, Shin SD, Song KJ, Lee EJ, Kim JY, et al. (2013) A trend in epidemiology and outcomes of out-of-hospital cardiac arrest by urbanization level: a nationwide observational study from 2006 to 2010 in South Korea. Resuscitation 84(5): 547-557. 